\title{
Моделирование волоконного оптического параметрического генератора для КАРС
}

\author{
А.А. Антропов ${ }^{*}$ В.Д. Ефремов, Е.А. Евменова, Д.С. Харенко \\ Институт автоматики и электрометрии СО РАН \\ *E-mail: antropovaa@iae.nsk.su
}

DOI: $10.31868 /$ RFL2020.193-194

Когерентная антистоксовая рамановская спектроскопия (КАРС) является одним из передовых направлений как для идентификации молекулярных соединений и процессов, протекающих в них, так и для решения задач гистологии. Она хорошо подходит для проведения неинвазивных исследований биологических объектов. Данная сфера слабо развита в России, поэтому реализация современной установки, которая будет компактной, мобильной, стабильной от воздействий внешней среды (температуры, звуковых колебаний) и не требующей периодической юстировки, крайне актуальна.

В КАРС образец облучается двумя лазерными импульсами, совмещенными во времени и в пространстве, но отстроенными друг от друга по несущей частоте в диапазоне $800-3500 \mathrm{~cm}^{-1}$ [1]. В данном частотном диапазоне находятся большинство известных колебательных мод, по которым потом можно идентифицировать химический состав образца. Для реализации полностью волоконной версии параметрического генератора можно использовать фотоннокристаллическое волокно (ФКВ), в котором преобразование длин волн осуществляется за счет четырехволнового смешения (ЧВС) [2]. Преимущество параметрического генератора, построенного на данном типе волокна, заключается в наличии большой области фазового синхронизма, следовательно, широкой области спектральной перестройки, его компактности и высокого качества генерируемой поперечной моды. За счет изотропии в оптических волокнах отсутствует нелинейность второго порядка, свойственная для кристаллов, а эффект ЧВС, как и прочие нелинейные эффекты, обеспечивается нелинейностью третьего порядка. Несмотря на то, что величина $\square^{3}$ в оптическом волокне ниже характерной величины $\square^{2}$ в кристаллах, преимуществом является тот факт, что в волокнах получается существенно большая длина взаимодействия излучения [3].

В нашей схеме излучение из задающего генератора диссипативных солитонов, проходя узкополосный перестраиваемый фильтр и каскады усиления, попадает в волоконный оптический параметрический генератор (ВОПГ), в состав которого входит ФКВ (LMA-5 PM), в котором и происходит процесс параметрической генерации [4]. Теоретические оценки показали, что имеющейся пиковой мощности достаточно для параметрической генерации в ФКВ, однако, мы столкнулись с тем, что в зависимости от длины ФКВ возникали конкурирующие по порядку нелинейности оптические эффекты. Так при длине ФКВ 5 метров наблюдалась генерация суперконтинуума, а при длине 1.5 м была наглядно видна нехватка пиковой мощности излучения накачки несмотря на то, что по оценкам пиковая мощность импульса достигала $\sim 1.8$ кВт. Поскольку экспериментальная оптимизация ВОПГ является крайне трудоёмкой задачей, было решено провести численное моделирование для поиска оптимальных характеристик накачки и генерируемого сигнала. Использовалась библиотека pyoffs, в которой реализовано решение нелинейного уравнения Шрёдингера с учётом дисперсии высоких порядков, потерь на разных длинах волн [5]. Проверка 
работоспособности данной библиотеки была проведена путем генерации спонтанного параметрического сигнала после прохождения нескольких метров ФКВ импульсом накачки с большой пиковой мощностью ( 1-2 кВт).

ВОПГ преобразован в модель кольцевого резонатора, параметры подобраны согласно схеме эксперимента (длины волокон, потери). Осуществлен поиск стационарного состояния и необходимого уровня энергии накачки, при котором будет наблюдаться стабильная параметрическая генерация. На Рис. 1 показаны характерные графики спектральной (слева) и временной (справа) зависимостей импульса параметрической генерации (на длине волны $\sim 800$ нм) относительно импульса накачки. Данные получены после 2000 проходов резонатора, когда относительное изменение энергии от обхода к обходу $\square$ Е/Е составляло величину не более $10^{-7}$.
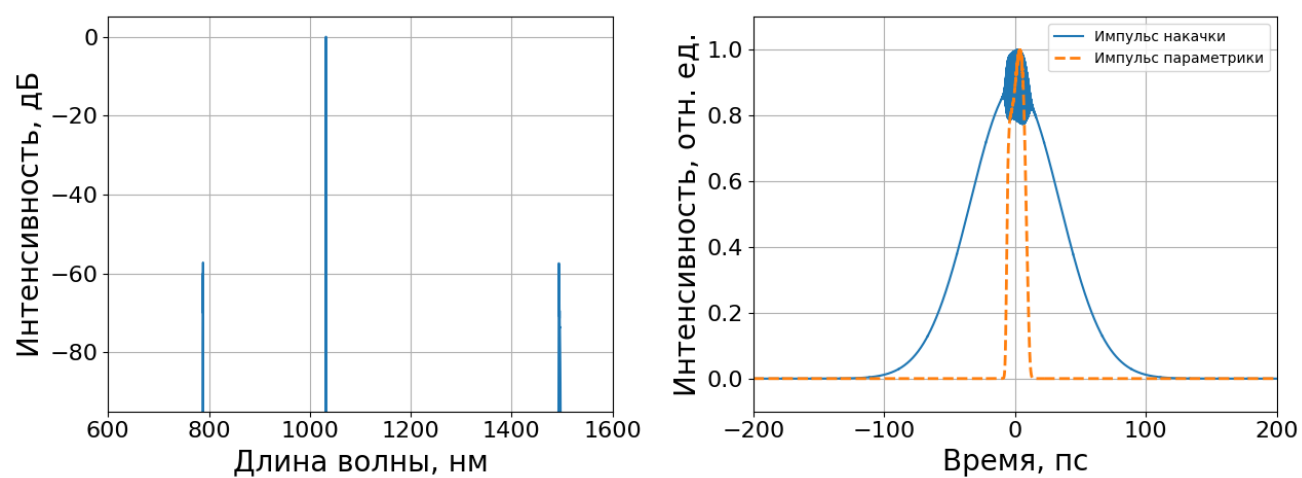

Рис. 1 Результаты расчетов. На левом рисунке показаны: основной пик - накачка на длине волны 1032 нм, дополнительные пики - параметрическая генерация. На правом показаны: синим - импульс накачки, оранжевым - импульс параметрической генерации.

Основной пик на левом графике относится к спектру импульса накачки, а боковые пики являются стоксовой и антистоксовой компонентами возникающего параметрического сигнала. На правом графике показаны возникающий параметрический импульс на 800 нм и импульс накачки. Результаты получены при пиковой мощности накачки 750 Вт и длительности импульсов 80 пс, длина ФКВ составляла 30 см. Сгенерированный импульс имеет длительность 16 пс и пиковую мощность $\sim 1$ Вт. На семинаре будут представлены результаты оптимизации ВОПГ по таким параметрам как длина ФКВ, пиковая мощность и длительность импульса накачки.

Исследование выполнено при финансовой поддержке РФФИ в рамках научного проекта № 20-32-70093.

\section{Литература}

[1] M Baumgartl, T. Gottschall et al, Opt. Express 20(19), 21010-21018 (2012)

[2] Е.А. Злобина, С.И. Каблуков, Автометрия 49, № 4 (2013)

[3] R. Stolen, IEEE Journal of Quantum Electronics, vol. 11, no. 3, 100-103, (1975)

[4] E. Evmenova, A. Antropov et al, Proc. SPIE 11190, (2019)

[5] https://github.com/galilley/pyofss 